\title{
EFL Learners Beliefs about Language Learning and their Relationship with Language Proficiency at Bisha University
}

Bader Fahed Al Slooli*

\author{
Ministry of Education - Bisha Governorate, Saudi Arabia; alslooli@hotmail.com
}

\begin{abstract}
Background/Objectives: To investigate the relationship between EFL learners' beliefs about language learning and their language proficiency. Methods/Statistical Analysis: The data were collected by two adapted versions of instruments 1 . A questionnaire, beliefs about language learning proficiency test. The questionnaire and proficiency test were administered to randomly selected 100 (50 male and 50 female) participants from the Department of Foreign Languages in the Faculty of Arts and Humanities at Bisha University. The researcher used the SPSS to find the Pearson Correlation Coefficient in order to find the Male and Female EFL Learners' beliefs about language learning and their relationship to language proficiency in Bisha University. Findings: There is a direct relation between the specific beliefs of the individuals (in both males and females) on learning English Language and the degree of efficiency of using the language. Therefore, the findings also showed that females have efficiency using the language of a much higher degree than males. Study concluded that not only the EFL learners' beliefs affect their practice of learning strategies, but their achievement in the language proficiency test plays a key role as well. Improvements/Applications: Updating language curriculum for English language learning courses so that these students develop an interest in the foreign language learning. Consult the English language learning specialist to propose multiple solutions that could help in overcoming problems and obstacles faced by Saudi EFL learners in their English writing expression in terms of vocabulary, grammar and translation, etc.
\end{abstract}

Keywords: BALLI, Bisha University, Cronbach Alpha. EFL, SPSS

\section{Introduction}

In a traditional classroom setting, the educational approach is usually teacher-centered that focuses on instructional activities and pattern drills. However, some students may not understand language learning in this way. For this reason, teachers are likely to meet students' expectations with the help of their own teaching practices or students may lose their confidence in language learning $\stackrel{1-3}{ }$. This lost confidence would develop negative beliefs that will limit their ultimate achievement. For students, the procedure of exploring beliefs can allow them to understand themselves more in the learning process ${ }^{4}$. This process of exploring beliefs is the best way to guide students, both inside and outside the classroom setting, more effectively about the language learning process and facilitate learning with greater self-knowledge and autonomy ${ }^{5}$.

Many studies have been conducted on the language learning beliefs and their impact on student learning ${ }^{6,7}$. The findings of such studies indicate that the linguistic information of students differ according to the attention they give to a task and the strategies they use to perform a task ${ }^{5}$. It had been observed that people who have positive attitudes of openness and curiosity, readiness to suspend disbelief or judgment regarding others' meanings, behaviors and beliefs are more successful in their oral proficiency of a foreign language ${ }^{8}$.

*Author for correspondence 
It is quite clear for the researcher that the learner's beliefs have an important role in their experience, success or failure as language learners. An understanding of learners' beliefs related to language learning processes can provide the educators with a better understanding of their expectations, dedication levels and satisfaction from foreign language learning classes. Based on the learner's beliefs, the teachers can decide on constructive teaching practices and methodologies. In addition, they can have more flexible and rational approach in organizing learning opportunities for their lessons?

\section{Statement of the Study Problem}

Individual beliefs and the foreign language learning are closely related. Considering the classroom context, students' perceptions, their beliefs, meta-cognitive processes to acquire knowledge and attitudes they bring along with them to the learning institution is recognized as an important factor contributing to their successful learning processes. Beliefs of the students regarding their language learning may have a direct impact on their learning performance in their classrooms. For example, if a student believes that he does not have a good aptitude for foreign language learning, he would not put more effort to learn that language. This is how, individual beliefs act as unlucky self-fulfilling predictions. The teachers must pay close attention to the students' beliefs to assess whether these beliefs have a positive or a negative influence on their learning capabilities ${ }^{10}$.

Learners of foreign language usually have certain beliefs, ideas and opinions related to foreign language learning based upon their personal experiences and the exposure they get from learning environments including both formal and informal ${ }^{11}$.

Considering the fact that the students have gained a lot of experiences throughout their educational career, chances are high that they can build their very own beliefs in reference to the features and factors that affect the perceptual process can make any learning process effective or ineffective ${ }^{12}$. This effective or ineffective learning can also be influenced by factors such as anxiety or motivation. Based upon this assumption, the present study has been designed to focus on the given study problem and is an attempt to investigate the potential relationship between beliefs and its influence on the learning outcomes of foreign language learners. The study also aims to investigate the EFL learner's beliefs and their connection with English language proficiency.

"Foreign Language learning depends largely upon the beliefs, attitudes and behavior of the students who decide to get enrolled in this program. However, the process of learning a foreign language is also influenced by a number of factors such as anxiety or motivation that can limit or encourage the students' learning ability of a foreign language" 13 .

This study is comprised of a few questions including what are the beliefs of male and female EFL learners on the subject of language learning? What is a relationship between beliefs of male and female EFL students and the overall English proficiency?

What is the difference between the beliefs of male EFL learners and that of female's about foreign languagelearning process? And are there any significant differences in the language proficiency test that could be referred to gender variable? Also examine the following hypotheses:

- The First Hypothesis: There is a significant statistical difference at $\alpha=0.01$ significance level between male and female students' beliefs about foreign language learning in favor of female ones.

- The Second Hypothesis: There is a statistical significant relationship between beliefs of male and female EFL students and the overall English proficiency

\section{Literature Survey}

$\operatorname{In} \underline{14}$ claimed that People's perception about their abilities, is therefore, increased when they achieve success and provided their personal competence was involved in their success rather than factors outside their control. Individual successful language learning experiences have a great impact on the observers as the observers may believe that the model is similar to themselves in terms of ability and competence. This perceived similarity between the model and the observer can guide the observer to believe that they may also employ similar strategies to achieve the same level of success. Persuasion, by presenting personal ideas impressions and self-experience in language learning, is also another factor that can influence to convey messages to people about their beliefs and expectations concerning one's abilities. Persuasion can be negative or positive, depending on the strength of arguments utilized in the persuasion process. However, negative influence seems to 
have a greater lowering effect on a person than positive persuasion has on heightening it, yet the impact of persuasion, positive or negative, is completely dependent on the person's reliability who is delivering that message in the eyes of the person who is receiving it. Anxiety can also alter the person's emotional state and can play a role in people's perceptions. Anxiety is strongly related to the current study due to its effect extends to the learners' communication skills, their tests achievement and their fear of negative evaluation.

In ${ }^{15}$ claimed that the learners play the main role in any type of learning environment. Students have positive or negative attitudes towards the language they want to learn. Having a positive attitude towards language learning is claimed to be one of the most important reasons that could improve the performance of foreign language learners in the language tests.

In ${ }^{16}$ claimed that with the growing demand of learning English language in the world, the Kingdom of Saudi Arabia (KSA) has also realized the importance of learning English language for its people so that they are able to take part in international happenings. The ability of KSA nationals to learn English is an important factor to play a significant role in the country's prosperity in $21^{\text {st }}$ century.

$\mathrm{In}^{17}$ claimed that regarding foreign language research, motivation acts as a driving force to start to learn the foreign language, and then later becomes the impulsion to sustain a long and difficult language-learning process.

According to a study by $\frac{18}{}$, a significantly negative correlation exists between the anxiety of learning a second language and students language performance from the first to the last semester. The results of this study portrayed that the students who faced a high level of language anxiety scored bad grades as compared to their less anxious counterparts.

\section{Methodology of the Study}

The present study is administrated on quantitativequalitative method to analyze the results of study instruments. The quantitative approach had included the theoretical description of the study topic and the distribution of a pre-designed closed ended questionnaire. On the other hand, the qualitative approach explores man related aspects such as awareness, attitudes, beliefs and perceptions in their normal situation as they naturally exist.

\section{Numerical Results}

The present study is a primary research based upon analysis and the evaluation of the study questionnaire (an adoption of the Horwitz model of the Beliefs about language learning) and the Overall English Language proficiency test developed by ${ }^{2}$.

\subsection{Testing of the Hypotheses}

It was noted that there is a direct relation between the total scores of the proficiency test and the total male beliefs on learning a language with the value 0.264 .

Both the male and female respondents in this study believed that language learning is considered as dealing with the unfamiliar environment where the learner must make sense of through more exposure to the language and this more exposure would result in enhancing their language proficiency.

On the whole, it is concluded from the above that there exists a direct relation between the specific beliefs of the individuals (both in male and female) on learning English language and the degree of efficiency of using the language. So, this approves the first hypothesis of the current study.

\subsubsection{The First Hypothesis}

There are significant differences on 0.01 levels between male and female learners (BALLI) in favor of female learners.

Results shown in Table 1 reveal that, mean scores of the answers by female students for beliefs were highly compared to answers given by male ones so that females' answers tend to strongly agree to the male answers they tend to agree, which proves the hypothesis that there are differences in beliefs in favor of females, which means that females are likely than males to believe that students who learn a second language are more proficient in English language.

It has been observed from the above table that $\mathrm{t}$-test value, which was calculated for all BALLI, axes (general beliefs, specific beliefs and applying strategies) in case of assuming the variation is equal in more than (0.005) which verified the second hypothesis.

Both the male and female respondents in this study believed that language learning is considered as dealing with the unfamiliar environment where the learner must make sense of through more exposure to the language 
Table 1. Differences between male and female in beliefs about language learning

\begin{tabular}{|c|c|c|c|c|c|c|c|}
\hline & Gender & $\mathrm{N}$ & Mean & Std. Deviation & Std. Error Mean & & Sig. \\
\hline \multirow{2}{*}{ General.beliefs1 } & Male & 50 & 3.6450 & .33790 & .04779 & Equal variances assumed & $.026 * *$ \\
\hline & Female & 50 & 4.5550 & .20105 & .02843 & Equal variances not assumed & \\
\hline \multirow{2}{*}{ specific.beliefs1 } & Male & 50 & 3.6980 & .42064 & .05949 & Equal variances assumed & $.246^{* *}$ \\
\hline & Female & 50 & 4.5700 & .27866 & .03941 & Equal variances not assumed & \\
\hline \multirow{2}{*}{$\begin{array}{l}\text { Beliefs.About. } \\
\text { Applying. Strategies } 1\end{array}$} & Male & 50 & 3.7636 & .40239 & .05691 & Equal variances assumed & $.058^{*}$ \\
\hline & Female & 50 & 4.4655 & .28786 & .04071 & Equal variances not assumed & \\
\hline
\end{tabular}

*significant at the 0.05 level.

**significant at the 0.01 level.

Table 2. Differences in language proficiency between EFL male and female learners

\begin{tabular}{|c|c|c|c|c|c|c|c|c|}
\hline & Gender & Close test & Vocab & Grammar & Trans. A to E & $\begin{array}{c}\text { Trans. } \mathrm{E} \\
\text { to } \mathrm{A}\end{array}$ & $\begin{array}{c}\text { Total translation } \\
\text { score }\end{array}$ & $\begin{array}{c}\text { Total marks } \\
\text { ?/100 }\end{array}$ \\
\hline \multirow[t]{3}{*}{ Male } & Mean & 10.82 & 15.60 & 10.10 & 4.54 & 7.56 & 12.06 & 64.78 \\
\hline & $\mathrm{N}$ & 50 & 50 & 50 & 50 & 50 & 50 & 50 \\
\hline & Std. Deviation & 3.816 & 3.464 & 6.052 & 2.908 & 2.417 & 5.048 & 23.292 \\
\hline \multirow[t]{3}{*}{ Female } & Mean & 11.30 & 15.50 & 10.64 & 5.24 & 7.64 & 12.88 & 67.36 \\
\hline & $\mathrm{N}$ & 50 & 50 & 50 & 50 & 50 & 50 & 50 \\
\hline & Std. Deviation & 3.370 & 3.352 & 5.506 & 2.677 & 2.117 & 4.702 & 20.763 \\
\hline \multirow[t]{3}{*}{ Total } & Mean & 11.06 & 15.55 & 10.37 & 4.89 & 7.60 & 12.47 & 66.07 \\
\hline & $\mathrm{N}$ & 100 & 100 & 100 & 100 & 100 & 100 & 100 \\
\hline & Std. Deviation & 3.590 & 3.392 & 5.762 & 2.803 & 2.261 & 4.871 & 21.990 \\
\hline
\end{tabular}

**significant at the 0.01 level.

* significant at the 0.05 level.

and this more exposure would result in enhancing their language proficiency.

Generally, it is concluded from the above that there is a direct relation between the specific beliefs of the individuals (in both male and female) on learning English language and the degree of efficiency of using the language. Therefore, this approves the first hypothesis of the current study.

\subsubsection{The Second Hypothesis}

There are significant differences of 0.01 levels between male and female EFL learners in their language proficiency in favor of female learners.

It was observed from the Table 2 that the arithmetic average of the test amongst the male participants was $(64.78 \%)$ and was $(67.78 \%)$ amongst the female participants with a general average for both falling at (66.07\%).

The efficient use of language through sections set as shown in the above table and through the average total scores for males and females is clear to us that the average score obtained by the males is (64.7) and females was average scores in all the test sections are (67.3) This means that females have efficiency using the language of a much higher degree than male which validates the hypothesis.

The researcher had analyzed the study data by using SPSS software to get study results. The researcher had realized that the outcomes of the study in the Saudi context were somehow similar to what the researchers had published in other areas. What they concluded from data analysis that female learners perform better than male learners. Based on the learners' academic major and gender, it is obvious that the successful accomplishment of the female learners had been superior to male learners in the English performance test. Results implied that learners' gender is an important factor contributing to English language learning. Gender had been reported as an efficient factor affecting EFL learners' performance.

After using the SPSS program and getting the results, the researcher understood that the findings of the study 
in the Saudi context were somehow like what had been published by other researchers in other areas. What they got from the analyses is the fact that female students at both the levels outperform male students. According to Majors and Gender, it clearly showed that the success of the total females was better than males in all regions in their EFL achievement test. The results implied that gender is a factor which is concerned with EFL learning. Gender was found to have significant effect on students' EFL achievement test.

\section{Conclusion and Recommendations}

The data about student' beliefs was divided into two categories: The general beliefs and specific beliefs so as to find out whether the participants had positive or negative beliefs on the items mentioned under each category. The significance value was calculated and observed for each item through the correlation coefficient by applying Cronbach Alpha. The analysis of the correlation coefficient showed almost all items at the 0.01 level of significance and thus implied the presence of a high degree of correlation between hub phrases.

The average mean scores regarding the general and specific beliefs of the EFL learners indicated that most males 'agree' to the items mentioned under each category. This implied that males generally believed that 'English is an easy language to learn as compared to other languages. The male participants also agreed on general beliefs that 'it is better to learn a foreign language in a foreign country' and accepted that it is 'easy to speak than to understand a foreign language'. Regarding the specific beliefs, the average mean scores indicated that most males agreed that they 'get self-conscious while speaking English'. However, they still believed that 'knowing English language will help them understand its speakers better'.

The average mean scores implied that most males had agreed that 'Everyone can learn and speak a foreign language' and 'people who speak more than one language are intelligent people. The average scores for general beliefs were 3.64 and for specific belief were (3.69). The overall results in both these categories for male participants showed that they had positive evaluations of their own language learning abilities and believed that English language acquisition is important to understand the English culture and also to get a good job.
The data regarding the general and specific beliefs of the female participants showed a high average of agreement than the male participants. The female participants 'strongly' agreed to most items under each of the discussed categories. Regarding the general beliefs, females strongly agreed that learning English for them is easy as 'women are better than men in learning a foreign language.'

The female participants showed strong agreement on the average specific beliefs about English languagelearning with higher mean scores than males on the items regarding 'ultimately learning the English language well' and on 'having a high aptitude for English language learning.

The female respondents also gave strong weight age to the fact that Saudis think that it is important to learn a foreign language. Overall, a highly positive response was observed by the females on most items of both the categories showing an average mean score of 4.57 for general beliefs and 4.55 for specific beliefs. Therefore, significant level of differences was observed in the responses of both male and female participants, with female females having a high level of difference in their responses in comparison to males.

Beliefs on the use of strategies to be applied to improve English Language learning (in male and female participants):

The data regarding beliefs on the use of strategies being applied to improve the English language learning by the male participants showed that the male participants had agreed with the importance of speaking a foreign language fluently and correctly. The results indicated that the participants had accepted that knowing a culture is imperative to learn a foreign language. The male participants of the study also accepted that 'learning new vocabulary', 'repeating and practicing a language,' 'learning grammar rules' are the strategies that can be adopted by them to improve their English language learning.

However, the average mean scores of the items under this category for males were (3.76) which was lower than females.

The results concerning the beliefs on the use of strategies being applied to improve the English language learning by the female participants indicated that female participants had believed that 'it is important to speak English language with a foreign accent' and had realized that they should not say anything in English till they can't say it correctly. The female respondents also conveyed 
their willingness to go up to the native speakers to learn to speak the English language correctly.

Most of the respondents accepted that to learn a foreign language correctly it is necessary that they should 'learn new vocabulary', 'repeat and practice' and learn its 'grammar rules.' They also believed that a foreign language is learnt well when it's practiced in a 'language laboratory.' The average mean scores of the items under this category for females was 4.46 which is higher than males proving that female participants showed significant difference in the level of both male and female participants with females having a high level of difference in their responses in comparison to males.

The data indicating the results of the Overall English language proficiency test amongst males showed that the average of the male participants on the cloze test scale was (10.82), on vocabulary it was (15.60), on Grammar (10). (10) and (12.06) was the average score in translation. For female participants, the response average scores of the Overall English language proficiency test for cloze test scale was (11.30), vocabulary scale score was (15.50), Grammar scale score was (10.64) and (12.88) was the average score in translation.

A comparison of the mean scores in both males and females' respondents indicate that the overall mean scores of the language proficiency test amongst females is higher than that of males except on the scale of vocabulary. This implies that female participants belonging to the present study have a better understanding of the language semantics including grammar and translation as compared to the male participants. However, the male participants show a better understanding on the vocabulary concepts when compared with females.

The finding suggests an addition of interesting activities by updating language curriculum for English language learning courses so that these students develop an interest in the foreign language learning. Consulting the English language learning specialist to propose multiple solutions that could help in overcoming problems and obstacles faced by Saudi EFL learners in their English writing expression in terms of vocabulary, grammar and translation etc. Recommending the teachers who are teaching the language courses at Bisha University, Department of languages, Faculty of Art and Humanities to pay more attention and investigate if there are any psychological issues among male students that could limit their language learning abilities.

\section{Acknowledgement}

This paper has been presented and discussed during the International Conference on Communication, Management and Information Technology - ICCMIT 2019, Vienna, Austria.

\section{References}

1. Horwitz E. Language anxiety and achievement. Annual Review of Applied Linguistics. 2001; 21:112-26. https://doi. org/10.1017/S0267190501000071

2. The Effect of Vocabulary Strategy Training on Enhancing Overall English Proficiency. 2004. https://translate.google. $\mathrm{com} /$ translate$? \mathrm{hl}=\mathrm{en} \& \mathrm{sl}=\mathrm{ar} \& \mathrm{u}=\mathrm{http}: /$ thesis.mandumah. com/Record/240276/Description\&prev=search

3. Mason GS, Shuman TR, Cook KE. Comparing the effectiveness of an inverted classroom to a traditional classroom in an upper- division engineering course. IEEE Transactions on Education. 2013; 56(4):430-5. https://doi. org/10.1109/TE.2013.2249066

4. Peacock M. Beliefs about language learning and their relationship to proficiency. International Journal of Applied Linguistics. 1999; 9(2):247-63. https://doi. org/10.1111/j.1473-4192.1999.tb00175.x

5. Secondary students' English language learning beliefs and oral proficiency: A Hong Kong case study. [Thesis]. 2002. http://hub.hku.hk/handle/10722/29572

6. Horwitz EK. The beliefs about language learning of beginning university foreign language students. The Modern Language Journal. 1988; 72(3): 283-94. https://doi. org/10.1111/j.1540-4781.1988.tb04190.x

7. Bernat E. Investigating Vietnamese ESL learners' beliefs about language learning. English Australia Journal. 2004; 21(2):40-54.

8. Gregersen T, Horwitz EK. Language learning and perfectionism: Anxious and non-anxious language learners' reactions to their own oral performance. The Modern Language Journal. 2002; 86(4):562-70. https://doi. org/10.1111/1540-4781.00161

9. English language learning beliefs, learning strategies and achievement of Masters students in Thailand. 2012. http:// www.tesol.org.au/files/files/275_kasma_suwanarak.pdf

10. Bernat E, Gvozdenko I. Beliefs about language learning: Current knowledge, pedagogical implications and new research directions. Teaching English as a Second or Foreign Language. 2005; 9(1):1-21.

11. Kayaoglu MN. Poor and good learners' language beliefs and their influence on their language learning strategy use. Novitas-ROYAL (Research on Youth and Language). 2013; 7(1):36-54. 
12. American Association for the Advancement of Science. 1990. https://history.aip.org/phn/21404002.html

13. Nespor J. The role of beliefs in the practice of teaching. Journal of Curriculum Studies. 1987; 19(4):317-28. https:// doi.org/10.1080/0022027870190403

14. Self-efficacy in Low-level English language learners. 2014. https://pdfs.semanticscholar.org/8718/e232a5053bafa7c3 17483431b6eb2f2078f5.pdf

15. Hosseini SB, Pourmandnia D. Language learners' attitudes and beliefs: Brief review of the related literature and frameworks. International Journal on New Trends in Education and Their Implications. 2013; 4(4):63-74.
16. Al-Asmari A, Khan M. World Englishes in the EFL teaching in Saudi Arabia. Arab World English Journal. 2014; 5(1):316-25.

17. Ghavamnia M, Kassaian Z, Dabaghi A. The relationship between language learning strategies, language learning beliefs, motivation and proficiency: A study of EFL learners in Iran. Journal of Language Teaching and Research. 2011; 2(5):1156-61. https://doi.org/10.4304/jltr.2.5.1156-1161

18. Horwitz E. Language anxiety and achievement. Annual Review of Applied Linguistics. 2001; 21:112-26. https://doi. org/10.1017/S0267190501000071 